\title{
MEMORANDUM
}

No 37/2000

THE MALLEABILITY OF UNDISCOUNTED UTILITARIANISM AS A CRITERION OF INTERGENERATIONAL JUSTICE

By

Geir B. Asheim and Wolfgang Buchholz

Department of Economics

University of Oslo 
This series is published by the

\section{University of Oslo} Department of Economics

P. O.Box 1095 Blindern

$\mathrm{N}-0317$ OSLO Norway

Telephone: +4722855127

Fax: $\quad+4722855035$

Internet: http://www.oekonomi.uio.no/ e-mail: $\quad$ econdep@econ.uio.no
In co-operation with

\section{The Frisch Centre for Economic} Research

$\begin{array}{ll}\text { Gaustadalleén } 21 & \\ \text { N-0371 OSLO Norway } & \\ \text { Telephone: } & +4722958820 \\ \text { Fax: } & +4722958825 \\ \text { Internet: } & \text { http://www.frisch.uio.no/ } \\ \text { e-mail: } & \text { frisch@frisch.uio.no }\end{array}$

List of the last 10 Memoranda:

\begin{tabular}{|l|l|}
\hline No 36 & $\begin{array}{l}\text { By Olav Bjerkholt: A turning point in the development of Norwegian } \\
\text { economics - the establishment of the University Institute of Economics in } \\
\text { 1932. 60 p. }\end{array}$ \\
\hline No 35 & $\begin{array}{l}\text { By Jon Strand: Tax distortions, household production } \\
\text { and black-market work. 33 p. }\end{array}$ \\
\hline No 34 & $\begin{array}{l}\text { By Snorre Kverndokk and Knut Einar Rosendahl: CO } 2 \text { mitigation costs } \\
\text { and ancillary benefits in the Nordic countries, the UK and Ireland: A } \\
\text { survey. 53 p. }\end{array}$ \\
\hline No 33 & $\begin{array}{l}\text { By Jon Strand: Competitive effort and employment determination } \\
\text { with team production. 25 p. }\end{array}$ \\
\hline No 32 & $\begin{array}{l}\text { By Øyvind Eitrheim, Eilev S. Jansen and Ragnar Nymoen: Progress from } \\
\text { forecast failure - The Norwegian consumption function. 27 p. }\end{array}$ \\
\hline No 31 & $\begin{array}{l}\text { By Michael Hoel and Tor Iversen: Genetic testing when there is a mix of } \\
\text { public and private health insurance. 27 p. }\end{array}$ \\
\hline No 30 & $\begin{array}{l}\text { By Geir Høidal Bjønnes and Dagfinn Rime: Customer Trading and } \\
\text { Information in Foreign Exchange Markets. 38 p. }\end{array}$ \\
\hline No 29 & $\begin{array}{l}\text { By Geir Høidal Bjønnes and Dagfinn Rime: FX Trading... LIVE! } \\
\text { Dealer Behavior and Trading Systems in Foreign Exchange Markets. } \\
\text { 36 p. }\end{array}$ \\
\hline No 28 & $\begin{array}{l}\text { By Gunn Elisabeth Birkelund and Johan Heldal: Educational Homogamy } \\
\text { in Norway -trends and patterns. 17 p. }\end{array}$ \\
\hline No 27 & $\begin{array}{l}\text { By Halvor Mehlum, Karl Moene and Ragnar Torvik: Predator or Prey? } \\
\text { Parasitic enterprises in economic development. 24 p. }\end{array}$ \\
\hline
\end{tabular}

A complete list of this memo-series is available in a PDF® format at: http://www.oekonomi.uio.no/memo/ 


\title{
THE MALLEABILITY OF UNDISCOUNTED UTILITARIANISM AS A CRITERION OF INTERGENERATIONAL JUSTICE
}

\author{
GEIR B. ASHEIM AND WOLFGANG BUCHHOLZ
}

\begin{abstract}
We show within three technological environments that any efficient and non-decreasing allocation can be the unique optimum according to undiscounted utilitarianism for some choice of utility function.

Journal of Economic Literature Classification Numbers: D63, Q32

Keywords: Utilitarianism, Intergenerational justice
\end{abstract}

\section{INTRODUCTION}

In the theory of economic growth it is quite common to determine optimal growth programs by means of a discounted utilitarian criterion, where the positive discount rate reflects pure time preference. Future utilities of consumption measured on a cardinal scale are through discounting transformed into present values, the sum of which one seeks to maximize. Thus, discounted utilitarianism provides a class of objective functions that are often used for evaluating intertemporal choice.

Even though discounting has sometimes been considered as "irrational" in the context of individual decision-making, such impatience has still been accepted as a natural part of exogenously given individual preferences. When discounting, however, refers to future generations, some fundamental ethical problems seem to arise. In the case of intergenerational discounting it

Date: 16 November 2000

Addresses: Geir B. Asheim, Dept. of Econ., University of Oslo, P.O. Box 1095 Blindern, N-0317 Oslo, Norway. E-mail: g.b.asheim@econ.uio.no

Wolfgang Buchholz, Dept. of Econ., University of Regensburg, D-93040 Regensburg, Germany. E-mail: wolfgang.buchholz@wiwi.uni-regensburg.de

Acknowledgment: We have received helpful comments from Eric Rasmusen and Martin Weitzman as well as seminar participants at Harvard University and CESifo Munich. Financial support from the Research Council of Norway (Ruhrgas grant) is gratefully acknowledged. 
is natural to question whether it is fair to value the utility of future generations less than that of the present one. This criticism against discounting has a long tradition in economics, dating back at least to Pigou [22]. It was revitalized in the ongoing debate on sustainable development, which it is sometimes claimed - is in danger when discounting is applied. The proponents of intergenerational discounting, however, also turn to ethical reflections when they try to justify this procedure. Thus it appears that a deep ethical conflict is present in the debate of the discounting issue.

It is the aim of this paper to evaluate the use of discounting in utilitarian social criteria for choice between intergenerational allocations. As a first step, we retrace the ethical arguments of the opponents and the proponents of intergenerational discounting. As a second step we show that this debate might be considered misplaced as there is not much room for a serious controversy on the discounting question. In particular, in many important technological environments the undiscounted utilitarian criterion is sufficiently malleable to allow for the choices the proponents of intergenerational discounting seeks to implement by discounting future utilities.

\section{Intergenerational Discounting AS AN ETHICAL PROBLEM}

The position of the opponents against intergenerational discounting is primarily based on the view that it is not a priori justified to give different

generations unequal weight in social evaluations as - in the light of some principle of insufficient reason - they do not seem to be fundamentally different, at least if population size is constant and there is no uncertainty. The only obvious distinction between members of different generations is that they do not appear simultaneously on the time axis, which, however, does not provide an ethically compelling reason for unequal treatment. If, under otherwise identical circumstances, welfare comparisons are to be made in a static context with a finite number of agents living within the same generation, one would not usually deny that equal individuals should get equal consideration in social welfare functions. Therefore, it is quite standard in welfare economics to adopt an anonymity principle by which discrimination of particular agents is excluded.

However, discounting does not only seem questionable from its normative basis but also from its consequences in some technological environments. 
When, e.g., the level of production does not only depend on man-made capital and labor, but also on the input of an exhaustible natural resource (like oil), applying a discounted utilitarian criterion for any time-invariant and strictly positive discount rate will, in the long run, force the consumption level to approach zero, even though positive and non-decreasing consumption is technically feasible. Thus, in such a Dasgupta-Heal-Solow technology constant and positive utility discounting leads to an outcome which does not appeal to commonly shared ethical intuitions, and which is not compatible with sustainable development - i.e. with having no generation enjoy a level of well-being that cannot be shared by future generations.

As appealing as these ethically motivated arguments against intergenerational discounting may look, there are also important arguments in favor of the position of the proponents of discounting.

The first of these arguments is of a technical nature. If the world does not come to its end at some predetermined date, it is an ethical imperative to take all these generations into consideration, which is well in line with the advocates of sustainability. But it is just the fact that the number of generations are modeled to be infinite that creates specific problems in making welfare comparisons. In the infinite case the existence of a socially most preferred intergenerational allocation cannot be ensured in the same way as it is usually done in the finite case, where the Weierstrass theorem easily applies. This theorem says that on a compact domain a continuous real valued function will have at least one maximum. In the finite case, not very demanding assumptions are needed to ensure that the premises of this theorem hold so that the existence of maximal elements is ensured. In the infinite case, however, it is not possible - in relevant technological environments - to have compactness of the set of feasible allocations and, at the same time, continuity of social preferences that are sensitive to the interest of each generation and treat all generations equally (cf. Koopmans [17] and Diamond [12]). Sensitivity here refers to the 'Strong Pareto' axiom (which we will also call 'Efficiency'), meaning that social preferences must deem one allocation superior to another if at least one generation is better off and no generation is worse off, while equal treatment refers to the 'Weak anonymity' axiom (which we will also call 'Equity'), meaning that social preferences must leave the social valuation of an allocation unchanged when 
the consumption levels of any two generations along the allocation are permuted. The undiscounted utilitarian criterion does, of course, satisfy these axioms. That this way of establishing existence cannot be generalized to the infinite case if 'Equity' is postulated explains some of the scepticism people have with this normative precept in the infinite number case. From this perspective adhering to this axiom may seem rather pointless if it is difficult to make use of it.

The second argument, however, for the widespread refusal of the 'Equity' axiom in the intergenerational context flows from more direct ethical reservations. In particular, it is claimed that equal treatment is in conflict with finding an acceptable balance between the interests of different generations. For many important classes of technologies (irrespective of the non-applicability of the Weierstrass theorem) it is well possible to find an ordering of feasible allocations that fulfills the 'Equity' axiom and determines a unique best element in the feasibility set. In particular, the undiscounted utilitarian criterion - appropriately adapted to the case with an infinite number of generations - will in many cases yield a unique optimal allocation. However, it is often claimed that the application of undiscounted utilitarianism leads to a distributional imbalance by impairing the earlier generations to an unacceptable degree. E.g., Rawls ([24], p. 287) argues that "the utilitarian doctrine may direct us to demand heavy sacrifices of the poorer generations for the sake of greater advantages for the later ones that are far better off", while Dasgupta and Mäler ([10], p. 2395) refers to calculations by Mirrlees [19] and Chakravarty [5] showing in plausible economic models that the present generation would be asked to save and invest around 50 percent of GNP under undiscounted utilitarianism. Thus, with a very productive economy, the danger exists that maximizing the sum of undiscounted utilities leads to a growth pattern that requires high savings rates initially and thereby imposes excessive hardships on earlier generations. Following such arguments, Rawls ([24], p. 297) reluctantly points out that "[t]his consequence can be to some degree corrected by discounting the welfare of those living in the future", and Arrow ([1], p. 16) concludes "that the strong ethical requirement that all generations be treated alike, itself reasonable, contradicts a very strong intuition that it is not morally acceptable to demand excessively high savings rates of any one generation, or even of every generation". To avoid consumption patterns that are too 
much to the disadvantage of earlier generations, the incorporation of a positive discount rate into the utilitarian criterion is thus considered inevitable. Stated in another way, this justification of utility discounting entails that discounting is not only required in order to be able to make choices at all, but also to ensure that the chosen distributions are ethically acceptable.

The first of these arguments - namely the problem of existence when the axioms of 'Efficiency' and 'Equity' are imposed - has been considered in a previous work (Asheim, Buchholz and Tungodden [3]). There we show that the axioms of 'Efficiency' and 'Equity' are not incompatible with the existence of maximal allocations, given that one considers technologies that are productive in the sense of satisfying the conditions of 'Immediate productivity' and 'Eventual productivity'. ${ }^{1}$ In fact, we show that any efficient and non-decreasing allocation is maximal if the social preferences over infinite intergenerational allocations are generated by these axioms.

In the present paper we consider the second of these arguments. We show within three important classes of technologies that undiscounted utilitarianism is so flexible that any efficient and non-decreasing allocation can be the unique optimal intergenerational allocation under the utilitarian criterion provided that the utility function is appropriately chosen. This means that, for any member of these classes of technologies, any outcome consistent with 'Efficiency' and 'Equity' can be realized under undiscounted utilitarianism. Thus, undiscounted utilitarianism has no bite beyond these axioms. Hence, the problem with undiscounted utilitarianism is neither that it does not allow for optimal allocations nor that it leads to unequal distributions imposing a too heavy burden on the present generation. Rather, the problem is that it - as a class of orderings - does not limit the set of optimal allocations more than the axioms of 'Efficiency' and 'Equity' do.

Throughout the well-being of any generation will be measured by a onedimensional indicator 'consumption', which comprises everything that affects a generation's livelihood. It is appropriate to think of 'consumption' as the money metric utility that a generation derives from the goods and services at its disposal, with the money metric utility function being identical for all generations. Even though we will prove (cf. Prop. 2) within three

\footnotetext{
${ }^{1}$ 'Immediate productivity' means that there are negative transfer costs from the present to the future if the future is worse off than the present, and 'Eventual productivity' means that there exist efficient and completely egalitarian allocations.
} 
classes of technologies that any efficient and non-decreasing allocation is compatible with zero utility discounting, any such allocation will be characterized by a positive consumption interest rate that cannot decrease too fast (cf. Prop. 1). Our analysis is therefore not an argument against positive discounting in social cost-benefit analysis, even for decisions relating to long-term environmental policy (e.g. controlling the greenhouse effect). However, the consumption interest rate - which will reflect net capital productivity - will be of a magnitude and have a time structure ${ }^{2}$ so that the decisions taken will not undermine the livelihood of future generations.

In the analysis of the present paper the concavity of the utility function $u$ represents the aversion in social evaluation towards inequality between generations. Hence, $u$ is not a von Neumann-Morgenstern utility function, where the corresponding concavity would be an expression of risk aversion. If risk and uncertainty were introduced into our analysis, it would still be appropriate in principle to distinguish between inequality aversion and risk aversion (cf. Kreps and Porteus [18]), although this is often not done in practical applications. Furthermore, even if one follows Harsanyi [15] in arguing that undiscounted utilitarianism derives its justification from hypothetical decisions under uncertainty in the original position, the risk aversion in his setting relates to decision problems that are not faced by actual decisionmakers. We therefore claim that the concavity of the utility function $u$ in the undiscounted utilitarian criterion is not observable in a market economy.

The paper is organized as follows. Section 3 contains a simple numerical illustration, and Section 4 describes the three classes of technologies that we will consider. Section 5 explains how the utilitarian criterion is extended to the evaluation of intergenerational allocations with an infinite number of generations. The main result is then presented in Sect. 6, while the concluding Sect. 7 contains a discussion of the results.

\section{A NUMERICAL ILLUSTRATION}

The main argument presented in the present paper is that, within certain technological environments, any efficient and non-decreasing allocation can be realized under undiscounted utilitarianism. This means that - given such a technological environment - an undiscounted utilitarian criterion can

\footnotetext{
2It may to some extent decrease over time. This is called "slow" (or hyperbolic) discounting (cf. e.g. Weitzman [29]).
} 
be substituted for any discounted utilitarian criterion that yields a nondecreasing allocation, without affecting the optimal allocation. The present section illustrates this possibility within a simple setting where there are only two generations. Let $c_{1}$ and $c_{2}$ denote consumption (or well-being) of generations 1 and 2, and let the set of feasible allocations be given by:

$$
\left(c_{1}, c_{2}\right) \geq 0 \text { is feasible if and only if } c_{1}+\frac{1}{4} c_{2} \leq 2 .
$$

This linear technology implies that the net capital productivity equals 3 $(=4-1)$. Let $u$ be the time-invariant utility function and let $\delta(\in(0,1])$ be the discount factor. This means that the utility discount rate equals $1 / \delta-1$. An allocation $\left(c_{1}, c_{2}\right)$ is a utilitarian optimum if and only if $\left(c_{1}, c_{2}\right)$ solves

$$
\max _{c_{1}^{\prime} \geq 0, c_{2}^{\prime} \geq 0} u\left(c_{1}^{\prime}\right)+\delta u\left(c_{2}^{\prime}\right) \text { s.t. } c_{1}^{\prime}+\frac{1}{4} c_{2}^{\prime} \leq 2 .
$$

This means that if $\left(c_{1}, c_{2}\right) \gg 0$, then $\left(c_{1}, c_{2}\right)$ satisfies $u^{\prime}\left(c_{1}\right)=\delta 4 u^{\prime}\left(c_{2}\right)$.

We can now verify that $\left(c_{1}, c_{2}\right)=(1,4)$ is a utilitarian optimum under both of the following constellations of utility function and discount factor:

$$
\begin{gathered}
u(c)=c^{1 / 2} \text { and } \delta=1 / 2 \\
u(c)=\ln c \text { and } \delta=0
\end{gathered}
$$

This illustrates how a more concave utility function can substitute for discounting along an allocation where consumption is strictly increasing.

\section{Three Classes of teChNOLOGIES}

In this section we will consider three important classes of technologies and show - within these classes - that efficient and non-decreasing allocations can be characterized in a straightforward manner. In any of these technologies we assume that gross output $y_{t}$ and consumption $c_{t}$ in period $t=0,1,2$ are one-dimensional. Furthermore, $k_{t}$ will denote invested man-made capital, i.e. the gross output that is not consumed. Write ${ }_{0} y=\left(y_{0}, y_{1}, \ldots\right)$ and correspondingly for other sequences. Refer to ${ }_{0} c=\left(c_{0}, c_{1}, \ldots\right)$ as an allocation. An allocation ${ }_{0} c=\left(c_{0}, c_{1}, \ldots\right)$ is said to be non-decreasing if $c_{t+1} \geq c_{t}$ for all $t \geq 0$ and stationary if $c_{t+1}=c_{t}$ for all $t \geq 0$. Given a set of feasible allocations, a feasible allocation ${ }_{0} c=\left(c_{0}, c_{1}, \ldots\right)$ is said to be efficient if there exists no alternative feasible allocation ${ }_{0} c^{\prime}=\left(c_{0}^{\prime}, c_{1}^{\prime}, \ldots\right)$ with $c_{t}^{\prime} \geq c_{t}$ for all $t \geq 0$, with strict inequality for some $t$. 
An arbitrary member of the three classes of the technologies will satisfy the conditions of 'Immediate productivity' and 'Eventual productivity' (in the terminology of Asheim et al. [3]) under given assumptions. Immediate productivity means that if ${ }_{0} c=\left(c_{0}, c_{1}, \ldots, c_{t}, c_{t+1}, \ldots\right)$ is feasible and $c_{t}>c_{t+1}$, then ${ }_{0} c^{\prime}=\left(c_{0}, c_{1}, \ldots, c_{t+1}, c_{t}, \ldots\right)$ is feasible and inefficient. Eventual productivity means that that there, for any initial condition, exists an efficient and stationary allocation ${ }_{0} c=(c, c, \ldots)$.

4.1. Linear technologies. A technology is linear if, in any period, the ratio of gross output and invested man-made capital is fixed and equal to $a_{t}$. On the other hand, this gross productivity factor can vary between periods. We assume positive net capital productivity:

$$
a_{t}>1 \text { for all } t>0 \text {. }
$$

This assumption means that the condition of 'Immediate productivity' is satisfied. Let the transformation set $\mathcal{T}_{t}^{1}$ in period $t$ be given by

$$
\mathcal{T}_{t}^{1}=\left\{(k, y) \mid 0 \leq y \leq a_{t} k\right\} .
$$

Let $y>0$. A program $\left(0 y,{ }_{0} k\right)$ is said to be $y$-feasible if

$$
y_{0}=y, \quad \text { and } \quad k_{t} \leq y_{t} \text { and }\left(k_{t}, y_{t+1}\right) \in \mathcal{T}_{t}^{1} \text { for all } t \geq 0 .
$$

An allocation ${ }_{0} c$ is said to be $y$-feasible if there is a $y$-feasible program $\left({ }_{0} y,{ }_{0} k\right)$ such that $c_{t}=y_{t}-k_{t}$ for all $t \geq 0$.

A linear technology determines a unique sequence of consumption discount factors $0 p=\left(p_{0}, p_{1}, \ldots\right)$ as follows:

$$
p_{0}=1 \quad \text { and } \quad p_{t+1} a_{t}=p_{t} \text { for all } t \geq 0 .
$$

Note that it holds for all $t \geq 0$ that $0<p_{t+1}<p_{t}$ since $a_{t}>1$. The following result is useful for the main result of this section.

Lemma 1. An allocation ${ }_{0} c$ is $y$-feasible if and only if $c_{t} \geq 0$ for all $t \geq 0$ and $\sum_{t=0}^{\infty} p_{t} c_{t} \leq y$.

Proof. Assume that ${ }_{0} c$ is $y$-feasible. Then there exists a $y$-feasible program $\left({ }_{0} y,{ }_{0} k\right)$ such that $c_{t}=y_{t}-k_{t} \geq 0$ for all $t \geq 0$. In particular, $y_{t+1} \leq a_{t} k_{t}$ for all $t \geq 0$. This means that $\sum_{t=0}^{T-1} p_{t+1} y_{t+1} \leq \sum_{t=0}^{T-1} p_{t+1} a_{t} k_{t}$. Since $p_{t+1} a_{t}=p_{t}$, this implies that $\sum_{t=0}^{T-1} p_{t}\left(y_{t}-k_{t}\right) \leq p_{0} y_{0}-p_{T} y_{T}$. We now obtain $\sum_{t=0}^{\infty} p_{t} c_{t} \leq y$ as $p_{t} c_{t}=p_{t}\left(y_{t}-k_{t}\right) \geq 0, p_{0} y_{0}=y$ and $p_{T} y_{T} \geq 0$. 
Assume that $c_{t} \geq 0$ for all $t \geq 0$ and $\sum_{t=0}^{\infty} p_{t} c_{t} \leq y$. Construct $\left({ }_{0} y,{ }_{0} k\right)$ by $y_{0}=y$, and $k_{t}=y_{t}-c_{t}$ and $y_{t+1}=a_{t} k_{t}$ for all $t \geq 0$. Then $p_{t} c_{t}+p_{t+1} y_{t+1}=$ $p_{t} y_{t}-p_{t} k_{t}+p_{t+1} a_{t} k_{t}=p_{t} y_{t}$, implying that $\sum_{s=t}^{\infty} p_{s} c_{s} \leq p_{t} y_{t}$. As $p_{s} c_{s} \geq 0$ for all $s \geq t$, it follows that $y_{t} \geq 0$ for arbitrary $t$, and $\left({ }_{0} y,{ }_{0} k\right)$ is $y$-feasible.

The set of efficient and non-decreasing $y$-feasible allocations is non-empty if the following condition holds

$$
\sum_{t=0}^{\infty} p_{t}<\infty
$$

since then the stationary allocation ${ }_{0} c=(c, c, \ldots)$ with $c=y /\left(\sum_{t=0}^{\infty} p_{t}\right)>0$ is $y$-feasible. If, on the other hand, (E.1) does not hold, then this set is empty. This means that a linear technology satisfies 'Eventual productivity' if and only if (E.1) is satisfied. An increasing sequence of gross productivity factors - i.e. ${ }_{0} a=\left(a_{0}, a_{1}, \ldots\right)$ satisfies $a_{t+1}>a_{t}$ for all $t \geq 0$ - can be interpreted as exogeneous technological progress. Condition (E.1) clearly holds if $a_{0}>1$ and ${ }_{0} a$ is non-decreasing.

4.2. Ramsey technologies. A Ramsey technology (cf. Ramsey [23]) is determined by a stationary production function $g: \mathbb{R}_{+} \rightarrow \mathbb{R}_{+}$that satisfies

$$
\begin{aligned}
& g \text { is concave, continuous for } k \geq 0, \\
& \text { and twice differentiable for } k>0 .
\end{aligned}
$$

$$
\begin{aligned}
& g(0)=0, \quad g^{\prime}>0 \text { for } k>0, \\
& g^{\prime}(k) \rightarrow \infty \text { as } k \downarrow 0 \quad \text { and } \\
& g^{\prime}(k) \downarrow 0 \text { as } k \rightarrow \infty .
\end{aligned}
$$

This assumption implies that the condition of 'Immediate productivity' (in the terminology of Asheim et al. [3]) is satisfied. Let the gross output function $f$ be given by $f(k)=g(k)+k$ for all $k \geq 0$. The transformation set $\mathcal{T}^{2}$ is time-invariant and is given by

$$
\mathcal{T}^{2}=\{(k, y) \mid 0 \leq y \leq f(k) ; k \geq 0\}
$$

Let $y>0$. A program $\left({ }_{0} y,{ }_{0} k\right)$ is said to be $y$-feasible if

$$
y_{0}=y, \quad \text { and } \quad k_{t} \leq y_{t} \text { and }\left(k_{t}, y_{t+1}\right) \in \mathcal{T}^{2} \text { for all } t \geq 0
$$


An allocation ${ }_{0} c$ is said to be $y$-feasible if there is a $y$-feasible program $\left({ }_{0} y,{ }_{0} k\right)$, where ${ }_{0} k$ is bounded above, ${ }^{3}$ such that $c_{t}=y_{t}-k_{t}$ for all $t \geq 0$.

A $y$-feasible program $\left({ }_{0} y,{ }_{0} k\right)$ is competitive if there is a non-null sequence of nonnegative prices ${ }_{0} p$ such that for $t \geq 0$,

$$
p_{t+1} y_{t+1}-p_{t} k_{t} \geq p_{t+1} y-p_{t} k \text { for all }(k, y) \in \mathcal{T}^{2} .
$$

In other words, along a competitive program intertemporal profits are maximized at each point in time. A competitive program is said to satisfy the transversality condition at the price sequence ${ }_{0} p$ if

$$
\lim _{T \rightarrow \infty} p_{T} k_{T}=0 .
$$

Lemma 2. Under (A.2), if a y-feasible and non-decreasing allocation ${ }_{0} c$ is efficient, then there exists a $y$-feasible program $\left({ }_{0} y,{ }_{0} k\right)$ with $c_{t}=y_{t}-k_{t}$ for all $t \geq 0$ that is competitive and satisfies the transversality condition at prices op given by

$$
p_{t+1} f^{\prime}\left(k_{t}\right)=p_{t} \quad \text { for } t \geq 0 .
$$

Furthermore, it holds that, for all $t \geq 0,0<p_{t+1}<p_{t}$, and $\sum_{t=0}^{\infty} p_{t} c_{t}<\infty$.

Proof. Assume that the $y$-feasible allocation ${ }_{0} c$ is efficient and non-decreasing. Construct $\left({ }_{0} y,{ }_{0} k\right)$ by $y_{0}=y$, and $k_{t}=y_{t}-c_{t}$ and $y_{t+1}=f\left(k_{t}\right)$ for all $t \geq 0$. Since ${ }_{0} c$ is $y$-feasible and efficient, it follows that there exists $\bar{k}$ such that $0<k_{t}<\bar{k}$ for all $t \geq 0$. Since, in addition, ${ }_{0} c$ is non-decreasing, it follows that $g\left(k_{t}\right)-c_{t+1}=k_{t+1}-k_{t} \geq 0$ for all $t \geq 0$. Determine a sequence of consumption discount factors ${ }_{0} p=\left(p_{0}, p_{1}, \ldots\right)$ as follows:

$$
p_{0}=1 \quad \text { and } \quad p_{t+1} f^{\prime}\left(k_{t}\right)=p_{t} \text { for all } t \geq 0 .
$$

Note that it holds for all $t \geq 0$ that $0<p_{t+1}<p_{t}$ since $f^{\prime}\left(k_{t}\right)=g^{\prime}\left(k_{t}\right)+1>$ 1. By the concavity of $g$ it follows that $\left({ }_{0} y,{ }_{0} k\right)$ is competitive. Since $k_{t}<\bar{k}$ for all $t \geq 0$, it follows that $\left({ }_{0} y,{ }_{0} k\right)$ satisfies the transversality condition: $p_{T} k_{T} \leq \delta^{T} \bar{k}$, where $\delta:=1 / f^{\prime}(\bar{k})$. Finally, since $c_{t} \leq g\left(k_{t-1}\right) \leq g(\bar{k})$ for all $t \geq 0$, it follows that $\sum_{t=0}^{\infty} p_{t} c_{t} \leq \sum_{t=0}^{\infty} \delta^{t} g(\bar{k})<\infty$.

The set of efficient and non-decreasing $y$-feasible allocations is non-empty since the stationary allocation $0 c=(c, c, \ldots)$ where $c>0$ solves $y=f(y-c)$

\footnotetext{
${ }^{3}$ I.e. given ${ }_{0} k$ there exists $\bar{k}$ such that $k_{t} \leq \bar{k}$ for all $t \geq 0$. This assumption is made in order for the Ramsey model to have 'finite consumption value' (i.e. $\sum_{t=0}^{\infty} p_{t} c_{t}<\infty$ ) and thereby enable Prop. 1 below to be established.
} 
is $y$-feasible. Hence, any Ramsey technology satisfies 'Eventual productivity'.

4.3. Dasgupta-Heal-Solow technologies. A Dasgupta-Heal-Solow technology (cf. Dasgupta and Heal [8] and Solow [26]) is determined by a stationary production function $G: \mathbb{R}_{+}^{3} \rightarrow \mathbb{R}_{+}$that satisfies

$G$ is concave, non-decreasing, homogeneous of degree one, and continuous for $(k, r, \ell) \geq 0$,

$G$ is twice differentiable

$$
\text { and satisfies }\left(G_{k}, G_{r}, G_{\ell}\right) \gg 0 \text { for }(k, r, \ell) \gg 0 \text {. }
$$

$G(k, 0, \ell)=0=G(0, r, \ell)$

Given any $\left(k^{\prime}, r^{\prime}\right) \gg 0$, there is $\eta^{\prime}>0$ such that for all $(k, r)$

satisfying $k \geq k^{\prime}, 0<r \leq r^{\prime}$, we have $\left[r G_{r}(k, r, 1)\right] / G_{\ell}(k, r, 1) \geq \eta^{\prime}$.

This assumption implies that the condition of 'Immediate productivity' is satisfied. Note that both capital $k_{t}$ and resource extraction $r_{t}$ are essential in production. The available labor force is assumed to be stationary and equal to 1. Still, labor needs to be explicitly considered in order to state the latter part of (A.3), namely that the ratio of the share of the resource in net output to the share of labor in net output is assumed to be bounded away from zero. Let the gross output function $F$ be given by $F(k, r)=G(k, r, 1)+k$ for all $(k, r) \geq 0$. The transformation set $\mathcal{T}^{3}$ is time-invariant and is given by

$$
\mathcal{T}^{3}=\left\{\left[(k, m),\left(y, m^{\prime}\right) \mid 0 \leq y \leq F(k, r) ; 0 \leq r=m-m^{\prime},\left(k, m^{\prime}\right) \geq 0\right\} .\right.
$$

Let $(y, m) \gg 0$, where $m$ is the available resource stock at time 0. A program $\left({ }_{0} y,{ }_{0} m,{ }_{0} k\right)$ is said to be $(y, m)$-feasible if

$$
\begin{gathered}
y_{0}=y \quad \text { and } \quad m_{0}=m \\
k_{t} \leq y_{t} \quad \text { and } \quad\left[\left(k_{t}, m_{t}\right),\left(y_{t+1}, m_{t+1}\right)\right] \in \mathcal{T}^{3} \quad \text { for all } t \geq 0 .
\end{gathered}
$$

An allocation ${ }_{0} c$ is said to be $(y, m)$-feasible if there is a $(y, m)$-feasible program $\left({ }_{0} y,{ }_{0} m,{ }_{0} k\right)$ such that $c_{t}=y_{t}-k_{t}$ for all $t \geq 0$.

A $(y, m)$-feasible program $\left({ }_{0} y,{ }_{0} m,{ }_{0} k\right)$ is competitive if there is a non-null sequence of nonnegative prices $\left({ }_{0} p,{ }_{0} q\right)$ such that for $t \geq 0$,

$$
\begin{gathered}
p_{t+1} y_{t+1}+q_{t+1} m_{t+1}-p_{t} k_{t}-q_{t} m_{t} \geq p_{t+1} y+q_{t+1} m^{\prime}-p_{t} k-q_{t} m \\
\text { for all }\left[(k, m)\left(y, m^{\prime}\right)\right] \in \mathcal{T}^{3} .
\end{gathered}
$$


A competitive program is said to satisfy the transversality condition at the price sequence $\left({ }_{0} p,{ }_{0} q\right)$ if

$$
\lim _{T \rightarrow \infty}\left(p_{T} k_{T}+q_{T} m_{T}\right)=0 .
$$

Lemma 3. Under (A.3), if a $(y, m)$-feasible and non-decreasing allocation ${ }_{0} c$ is efficient, then there exists a y-feasible program $\left({ }_{0} y,{ }_{0} m,{ }_{0} k\right)$ with $c_{t}=$ $y_{t}-k_{t}$ for all $t \geq 0$ that is competitive and satisfies the transversality condition at prices $\left({ }_{0} p,{ }_{0} q\right)$ given by

$$
\begin{gathered}
p_{t+1} F_{k}\left(k_{t}, m_{t}-m_{t+1}\right)=p_{t} \quad \text { for } t \geq 0 \\
q_{t}=q>0 \quad \text { and } \quad p_{t+1} F_{r}\left(k_{t}, m_{t}-m_{t+1}\right)=q \text { for } t \geq 0 .
\end{gathered}
$$

Furthermore, it holds that, for all $t \geq 0,0<p_{t+1}<p_{t}$, and $\sum_{t=0}^{\infty} p_{t} c_{t}<\infty$.

Proof. Let $s^{\prime \prime} \geq 0$ be the first period with positive consumption: $c_{s^{\prime \prime}}>0$ and $c_{t}=0$ for $0 \leq t<s^{\prime \prime}$. Then, by Prop. 2 in Dasgupta and Mitra [11], $k_{t+1}>k_{t}>0$ and $0<m_{t+1}<m_{t}$ for $t \geq s^{\prime \prime}$. Let $s^{\prime}$, where $0 \leq s^{\prime} \leq s^{\prime \prime}$, be the first period with positive extraction: $r_{s^{\prime}}=m_{s^{\prime}}-m_{s^{\prime}+1}>0$ and $r_{t}=m_{t}-m_{t+1}=0$ for $0 \leq t<s^{\prime}$. If $s^{\prime}>0$, then (A.3) implies that the resulting allocation is inefficient, since a Pareto-dominating allocation can be constructed by having $r_{s^{\prime}-1}^{\prime}=\epsilon>0$ and $r_{s^{\prime}}^{\prime}=r_{s^{\prime}}-\epsilon>0$ (for sufficiently small $\epsilon$ ) and reinvesting the additional output at time $s^{\prime}-1$. Thus, $s^{\prime}=0$.

Hence, $k_{t}>0$ and $r_{t}=m_{t}-m_{t+1}>0$ for $t \geq 0$. The result now follows from Thm. 4.1 and Cor. 4.1 in Mitra [20].

Assumption (A.3) is not sufficient to ensure the existence of a stationary allocation with positive consumption. Therefore assume the following condition.

There exists from any $(y, m) \gg 0$

a stationary allocation with positive consumption.

Dasgupta and Mitra [11] show within the setting of Dasgupta-Heal-Solow technologies that this implies the existence of an efficient and stationary allocation. This means that a Dasgupta-Heal-Solow technology satisfies 'Eventual productivity' and has a non-empty set of efficient and non-decreasing $(y, m)$-feasible allocations if (E.3) holds. We state (E.3) in its reduced form 
since it is outside the scope of the present paper to provide primitive technological conditions. ${ }^{4}$

The importance of Dasgupta-Heal-Solow technologies in a discussion of intergenerational justice derives from the property that net capital productivity $G_{k}(k, r, \ell)$ decreases and approaches zero along any efficient and nondecreasing allocation. This occurs in a stationary technology setting due to the dwindling availability of the resource.

\subsection{A characterization result for efficient and non-decreasing al-}

locations. Lemmas 1-3 mean that we can establish the following result.

Proposition 1. Assume (A.1)-(A.3). Consider a member of the classes of linear, Ramsey or Dasgupta-Heal-Solow technologies. If a y-feasible (or $(y, m)$-feasible) allocation ${ }_{0} c=\left(c_{0}, c_{1}, \ldots\right)$ is efficient and non-decreasing, then there exists a sequence of consumption discount factors ${ }_{0} p=\left(p_{0}, p_{1}, \ldots\right)$ satisfying $0<p_{t+1}<p_{t}$ for all $t \geq 0$ such that

$$
\infty>\sum_{t=0}^{\infty} p_{t} c_{t} \geq \sum_{t=0}^{\infty} p_{t} c_{t}^{\prime}
$$

for any $y$-feasible (or $(y, m)$-feasible) allocation ${ }_{0} c^{\prime}=\left(c_{0}^{\prime}, c_{1}^{\prime}, \ldots\right)$.

Proof. Part 1: Linear technologies. The result follows immediately from Lemma 1 , since $\sum_{t=0}^{\infty} p_{t} c_{t}=y(<\infty)$ if ${ }_{0} c$ is $y$-feasible and efficient, and $\sum_{t=0}^{\infty} p_{t} c_{t}^{\prime} \leq y$ if ${ }_{0} c^{\prime}$ is $y$-feasible.

Part 2: Ramsey technologies. Lemma 2 establishes the existence of a $y$ feasible program $\left({ }_{0} y,{ }_{0} k\right)$ with $c_{t}=y_{t}-k_{t}$ for all $t \geq 0$ that is competitive and satisfies the transversality condition at prices ${ }_{0} p$ satisfying $0<p_{t+1}<p_{t}$ for all $t \geq 0$ such that $\sum_{t=0}^{\infty} p_{t} c_{t}<\infty$. Furthermore,

$$
\begin{aligned}
\sum_{t=0}^{T} p_{t}\left(c_{t}^{\prime}-c_{t}\right) & =\sum_{t=0}^{T} p_{t}\left[\left(y_{t}^{\prime}-k_{t}^{\prime}\right)-\left(y_{t}-k_{t}\right)\right] \\
& \leq p_{0}\left(y_{0}^{\prime}-y_{0}\right)-p_{T}\left(k_{T}^{\prime}-k_{T}\right) \leq p_{T} k_{T},
\end{aligned}
$$

where ${ }_{0} c^{\prime}$ is any $y$-feasible allocation with $\left({ }_{0} y^{\prime},{ }_{0} k^{\prime}\right)$ as a corresponding $y$ feasible program, since $\left({ }_{0} y,{ }_{0} k\right)$ is competitive, $y_{0}^{\prime}=y_{0}=y$, and $p_{T} k_{T}^{\prime} \geq$ 0 . Finally, $\sum_{t=0}^{\infty} p_{t}\left(c_{t}^{\prime}-c_{t}\right) \leq 0$ since $\left({ }_{0} y,{ }_{0} k\right)$ satisfies the transversality condition.

Part 3: Dasgupta-Heal-Solow technologies. Lemma 3 establishes the existence of a $(y, m)$-feasible program $\left({ }_{0} y,{ }_{0} m,{ }_{0} k\right)$ with $c_{t}=y_{t}-k_{t}$ for all

\footnotetext{
${ }^{4}$ Cass and Mitra [4] give necessary and sufficient conditions on the production function $G$ for (E.3) to hold.
} 
$t \geq 0$ that is competitive and satisfies the transversality condition at prices $\left({ }_{0} p,{ }_{0} q\right)$, where ${ }_{0} p$ satisfies $0<p_{t+1}<p_{t}$ for all $t \geq 0$, such that $\sum_{t=0}^{\infty} p_{t} c_{t}<$ $\infty$. Furthermore,

$$
\begin{aligned}
\sum_{t=0}^{T} p_{t}\left(c_{t}^{\prime}-c_{t}\right) & =\sum_{t=0}^{T} p_{t}\left[\left(y_{t}^{\prime}-k_{t}^{\prime}\right)-\left(y_{t}-k_{t}\right)\right] \\
& \leq p_{0}\left(y_{0}^{\prime}-y_{0}\right)+q_{0}\left(m_{0}^{\prime}-m_{0}\right) \\
& \left.\quad-\left[p_{T}\left(k_{T}^{\prime}-k_{T}\right)\right]+q_{T}\left(m_{T}^{\prime}-m_{T}\right)\right] \\
& \leq p_{T} k_{T}+q_{T} m_{T},
\end{aligned}
$$

where ${ }_{0} c^{\prime}$ is any $(y, m)$-feasible allocation with $\left({ }_{0} y^{\prime},{ }_{0} m^{\prime},{ }_{0} k^{\prime}\right)$ as a corresponding $(y, m)$-feasible program, since $\left({ }_{0} y,{ }_{0} m,{ }_{0} k\right)$ is competitive, $y_{0}^{\prime}=$ $y_{0}=y, m_{0}^{\prime}=m_{0}=m$, and $p_{T} k_{T}^{\prime}+q_{T} m_{T}^{\prime} \geq 0$. Finally, $\sum_{t=0}^{\infty} p_{t}\left(c_{t}^{\prime}-c_{t}\right) \leq 0$ since $\left({ }_{0} y,{ }_{0} m,{ }_{0} k\right)$ satisfies the transversality condition.

\section{Evaluating Intergenerational Allocations}

The motivation for this paper is to show that - within the considered classes of technologies - any efficient and non-decreasing allocation is the unique optimum according to undiscounted utilitarianism for some choice of utility function. There are problems associated with this exercise.

1. In the context of an infinite number of generations the sum of undiscounted utilities will generally diverge. This means that one has to invoke the 'catching up' criterion, under which one allocation is as good as another if the liminf, as $T$ goes to infinity, of the sum up to time $T$ of the difference between the utilities generated by the allocations is nonnegative.

2. The utility function may have to be chosen such that marginal utility is zero beyond some consumption level. This means that undiscounted utilitarianism will not satisfy the axiom of 'Efficiency' (or 'Strong Pareto'; cf. Sect. 2) unless some amendment is introduced. An amendment that works is to the introduce a second order and strictly increasing utility function that is applied lexicographically to resolve ties.

3. Even with such lexicographic optimization, the resulting reflexive and transitive binary relation will not necessarily be complete. However, to complete the binary relation, one can invoke a result due to Szpilrajn $[28]$. 
Hence, the class of binary relations that we will consider consists of the following components:

- A first-order utility function $u: \mathbb{R}_{+} \rightarrow \mathbb{R}$ that is continuous, concave and non-decreasing, and which will be constructed for each efficient and non-decreasing allocation such that this allocation will be the unique utilitarian optimum.

- A second-order utility function $v: \mathbb{R}_{+} \rightarrow \mathbb{R}$ that is continuous and strictly increasing so that the axiom of 'Efficiency' is satisfied. For this purpose we will assume throughout that $v$ is given by $v(c)=c$.

- Given $u$, a complete and transitive binary relation $R_{u}$ that is a completion of 'catching up'-utilitarianism when these utility functions are used lexicographically.

We will first show how an incomplete reflexive and transitive binary relation $R_{u}^{*}$ can be constructed on the basis of $u$. Then we consider the issue of completing $R_{u}^{*}$ to $R_{u}$.

Let ${ }_{0} c^{\prime}=\left(c_{0}^{\prime}, c_{1}^{\prime}, \ldots\right)$ and ${ }_{0} c^{\prime \prime}=\left(c_{0}^{\prime \prime}, c_{1}^{\prime \prime}, \ldots\right)$ be two allocations. Let $u$ be given, and determine $R_{u}^{*}$ as follows.

$$
{ }_{0} c^{\prime} R_{u 0}^{*} c^{\prime \prime} \Leftrightarrow\left\{\begin{array}{l}
\liminf _{T \rightarrow \infty} \sum_{t=0}^{T}\left(u\left(c_{t}^{\prime}\right)-u\left(c_{t}^{\prime \prime}\right)\right) \geq 0, \\
\text { and } \liminf _{T \rightarrow \infty} \sum_{t=0}^{T}\left(v\left(c_{t}^{\prime}\right)-v\left(c_{t}^{\prime \prime}\right)\right) \geq 0 \\
\text { whenever } \sum_{t=0}^{\infty}\left(u\left(c_{t}^{\prime}\right)-u\left(c_{t}^{\prime \prime}\right)\right)=0 .
\end{array}\right.
$$

It is straightforward to show that $R_{u}^{*}$ is reflexive and transitive. Let $P_{u}^{*}$ and $I_{u}^{*}$ denote the asymmetric and symmetric parts of $R_{u}^{*}$, respectively; i.e. $P_{u}^{*}$ denotes (strict) preference, while $I_{u}^{*}$ denotes indifference. If ${ }_{0} c^{\prime}$ is derived from ${ }_{0} c^{\prime \prime}$ by having $c_{s}^{\prime}=c_{s}^{\prime \prime}+\epsilon, \epsilon>0$, and $c_{t}^{\prime}=c_{t}^{\prime \prime}$ for $t \neq s$, then ${ }_{0} c^{\prime} P_{u}^{*}{ }_{0} c^{\prime \prime}$ since - even if $u\left(c_{s}^{\prime}\right)=u\left(c_{s}^{\prime \prime}\right)$ - we do have that $v\left(c_{s}^{\prime}\right)>v\left(c_{s}^{\prime \prime}\right)$. This means that $R_{u}^{*}$ satisfies the axiom of 'Efficiency' (or 'Strong Pareto'). If ${ }_{0} c^{\prime}$ is derived from ${ }_{0} c^{\prime \prime}$ by having $c_{s^{\prime}}^{\prime}=c_{s^{\prime \prime}}^{\prime \prime}, c_{s^{\prime \prime}}^{\prime}=c_{s^{\prime}}^{\prime \prime}$, and $c_{t}^{\prime}=c_{t}^{\prime \prime}$ for $t \neq s^{\prime}, s^{\prime \prime}$, then ${ }_{0} c^{\prime} I_{u}^{*} c^{\prime \prime}$ since $\sum_{t=0}^{\infty}\left(u\left(c_{t}^{\prime}\right)-u\left(c_{t}^{\prime \prime}\right)\right)=0$ and $\sum_{t=0}^{\infty}\left(v\left(c_{t}^{\prime}\right)-v\left(c_{t}^{\prime \prime}\right)\right)=0$. This means that $R_{u}^{*}$ satisfies the axiom of 'Equity' (or 'Weak anonymity').

By invoking Svensson's [27] Thm. 2, there exists a complete and transitive binary relation $R_{u}$ which has $R_{u}^{*}$ as a subrelation. ${ }^{5}$ Svensson's [27] Thm. 2

\footnotetext{
${ }^{5} R^{\prime}$ is said to be a subrelation to $R^{\prime \prime}$ if (i) ${ }_{0} c^{\prime} R^{\prime}{ }_{0} c^{\prime \prime}$ implies ${ }_{0} c^{\prime} R^{\prime \prime}{ }_{0} c^{\prime \prime}$ and (ii) ${ }_{0} c^{\prime} P^{\prime}{ }_{0} c^{\prime \prime}$ implies ${ }_{0} c^{\prime} P^{\prime \prime}{ }_{0} c^{\prime \prime}$, with $P^{\prime}$ and $P^{\prime \prime}$ denoting the asymmetric parts of $R^{\prime}$ and $R^{\prime \prime}$, respectively.
} 
states that any reflexive and transitive binary relation that satisfies the axioms of 'Efficiency' and 'Equity' is a subrelation to a complete and transitive binary relation (i.e. an ordering). In proving this result Svensson refers to a general mathematical lemma by Szpilrajn [43]. Note that it follows from the definition of a subrelation that also $R_{u}$ satisfies the axioms of 'Efficiency' and 'Equity'. For our purpose we need not be concerned about how $R_{u}^{*}$ is completed to $R_{u}$. Because we will show that the considered efficient and decreasing allocation will $P_{u}^{*}$-dominate any alternative feasible allocation for an appropriately chosen $u$. Then it follows that the considered efficient and decreasing allocation will $P_{u}$-dominate any alternative allocation, independently of how $R_{u}^{*}$ is completed to $R_{u}$. We will refer to an ordering $R_{u}$ constructed as explained above as an extended undiscounted utilitarian criterion.

\section{Main Result}

We have in the two previous sections established the parts on which our main result will be based. We first characterized efficient and non-decreasing allocations in three important classes of technologies. We then formulated an undiscounted utilitarian criterion to evaluate intergenerational allocations with an infinite number of generations. We will in this section use these ingredients to show how any efficient and non-decreasing allocation in the context of any technology in these classes is the unique optimum according to undiscounted utilitarianism for some choice of utility function.

Proposition 2. Assume (A.1)-(A.3). Consider a member of the classes of linear, Ramsey or Dasgupta-Heal-Solow technologies. If a y-feasible (or $(y, m)$-feasible) allocation ${ }_{0} c=\left(c_{0}, c_{1}, \ldots\right)$ is efficient and non-decreasing, then there exists an extended undiscounted utilitarian criterion $R_{u}$ such that ${ }_{0} c P_{u} c^{\prime}$ for any $y$-feasible (or $(y, m)$-feasible) allocation ${ }_{0} c^{\prime}=\left(c_{0}^{\prime}, c_{1}^{\prime}, \ldots\right)$ that does not coincide with ${ }_{0} c$.

Proof. Since any $R_{u}^{*}$ can be extended to a complete and transitive binary relation $R_{u}$ to which $R_{u}^{*}$ is a subrelation, it is sufficient to show that there exists $u$ such that ${ }_{0} c P_{u}^{*}{ }_{0} c^{\prime}$ for any $y$-feasible (or $(y, m)$-feasible) allocation ${ }_{0} c^{\prime}$ (because ${ }_{0} c P_{u}^{*}{ }_{0} c^{\prime}$ implies ${ }_{0} c P_{u} c^{\prime}$ for any completion).

By Prop. 1 there exists a sequence of consumption discount factors ${ }_{0} p=$ $\left(p_{0}, p_{1}, \ldots\right)$ satisfying $0<p_{t+1}<p_{t}$ for all $t \geq 0$ such that $\infty>\sum_{t=0}^{\infty} p_{t} c_{t} \geq$ 


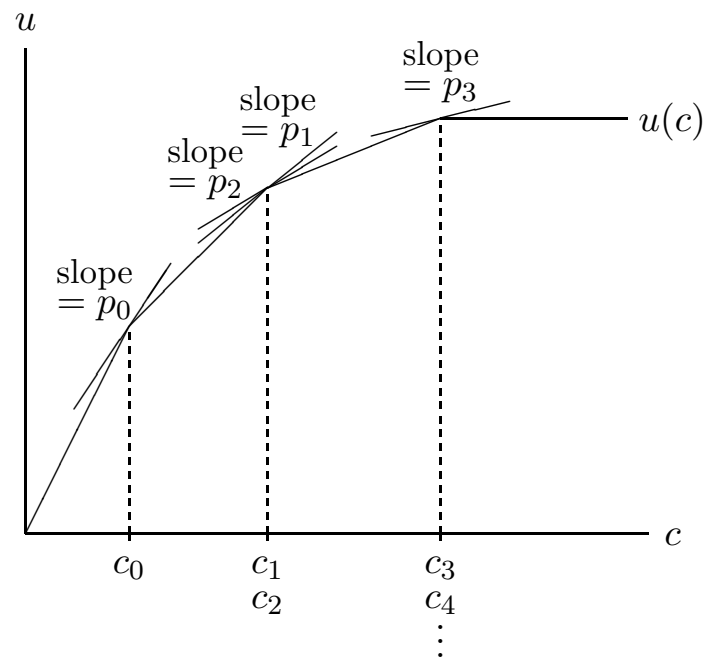

FiguRE 1. Illustration of the proof of Prop. 2.

$\sum_{t=0}^{\infty} p_{t} c_{t}^{\prime}$ for any $y$-feasible (or $(y, m)$-feasible) allocation ${ }_{0} c^{\prime}$. Construct a continuous, concave, and non-decreasing utility function $u$ as follows. Let

$$
u_{0} \in\left(p_{0}, \infty\right) \text { and } u_{t} \in\left(p_{t+1}, p_{t}\right) \text { for } t \geq 1 .
$$

If $0 \leq c<\sup \left\{c_{t} \mid t \in \mathbb{N}\right\}$, write $t^{c}:=\min \left\{t \in \mathbb{N} \mid c_{t} \geq c\right\}(\geq 0)$, and let

$$
u(c)=\sum_{t=0}^{t^{c}} u_{t} \cdot\left(c_{t}-c_{t-1}\right)-u_{t^{c}} \cdot\left(c_{t^{c}}-c\right),
$$

where $c_{-1}:=0$. Note that $u$ is a piece-wise linear, continuous and concave function, with $u(0)=0$ and with the slope on each linear segment $\left(c_{t}, c_{t+1}\right)$ lying strictly between $p_{t+1}$ and $p_{t}$. If $\sup \left\{c_{t} \mid t \in \mathbb{N}\right\}=\infty$, then $u$ has been constructed. Otherwise, write $\bar{c}:=\sup \left\{c_{t} \mid t \in \mathbb{N}\right\}$. Since $u$ is continuous and non-decreasing on $[0, \bar{c}), \lim _{c \uparrow \bar{c}} u(c)$ exists; write $\bar{u}:=\lim _{c \uparrow \bar{c}} u(c)$. Complete the construction of $u$ by setting $u(c)=\bar{u}$ for $c \geq \sup \left\{c_{t} \mid t \in \mathbb{N}\right\}$.

Note that $u$ is constructed so that, for each $t \geq 0$,

$$
u\left(c_{t}\right)-p_{t} c_{t} \geq u(c)-p_{t} c
$$

for any $c \geq 0$, with the inequality being strict if $c \neq c_{t}$. This implies that

$$
\liminf _{T \rightarrow \infty} \sum_{t=0}^{T}\left(u\left(c_{t}\right)-u\left(c_{t}^{\prime}\right)\right) \geq \sum_{t=0}^{\infty} p_{t}\left(c_{t}-c_{t}^{\prime}\right) \geq 0,
$$

for any $y$-feasible (or $(y, m)$-feasible) allocation ${ }_{0} c^{\prime}$, with the first inequality being strict if ${ }_{0} c \neq{ }_{0} c^{\prime}$. This means that ${ }_{0} c P_{u}^{*}{ }_{0} c^{\prime}$ if ${ }_{0} c \neq{ }_{0} c^{\prime}$. 
The construction of the continuous and piece-wise linear utility function $u$ is shown in Fig. 1, thereby illustrating the proof of Prop. 2. An extension of the preceding analysis shows that a differentiable utility function can be obtained if and only if ${ }_{0} c$ is strictly increasing.

\section{Discussion}

Our main result (Prop. 2) should not necessarily be interpreted as support for undiscounted utilitarianism. Rather, it is in some sense a converse of the result that we established in Asheim et al. [3]. There we showed that the rather uncontroversial ethical axioms of 'Efficiency' and 'Equity' rule out any allocation that is not efficient and non-decreasing in technologies that satisfy the conditions of 'Immediate productivity' and 'Eventual productivity'. All members of the three classes of technologies that we have considered here satisfy 'Immediate productivity' under the assumptions of (A.1)-(A.3), and they satisfy 'Eventual productivity' provided that (E.1) and (E.3) are satisfied. Hence, 'Efficiency' and 'Equity' alone rule out any allocation that is not efficient and non-decreasing. Here, we have showed within these technological environments that any efficient and non-decreasing allocation can be a unique undiscounted utilitarian optimum for an appropriate chosen utility function. Hence, the class of undiscounted utilitarian criteria - any member of which satisfies 'Efficiency' and 'Equity' - is sufficiently malleable to allow for any efficient and non-decreasing allocation to be the unique choice. This may be taken to mean that no efficient and non-decreasing allocation can be ruled out solely from ethical consideration, at least in the three classes of technologies that we consider.

This is a negative conclusion in the sense that adopting undiscounted utilitarianism as a class of social preferences does not indicate how to provide a sharper prescription for choice among feasible allocations - unless one has a specific ethical intuition concerning the concavity of the utility function which, however, seems hard to obtain on the basis of ethical axioms alone. In Ramsey technologies discounted utilitarianism with a positive and timeinvariant discount rate is one alternative that - even as an entire class of criteria - yields sharper prescriptions. Suppose that the discount rate is chosen to be smaller or equal to $g^{\prime}(k(y))$, where $k(y)$ solves $y=f(k(y))$ for given $y$. Then discounted utilitarianism applied to the Ramsey model will, quite independently of the shape of the utility function, lead to an efficient 
TABLE 1. Results on undiscounted and discounted utilitarianism.

\section{Ramsey technologies}

\section{Undiscounted utilitarianism}

\section{Discounted utilitarianism}

\author{
All allocations \\ consistent with
}

'Effic.' \& 'Equity'

\section{D-H-S technologies}

\author{
All allocations \\ consistent with
}

$$
\begin{array}{cc}
\text { More equal alloc. } & \text { No allocation } \\
\text { consistent with } & \text { consistent with } \\
\text { 'Effic.' \& 'Equity' } & \text { 'Effic.' \& 'Equity' }
\end{array}
$$

and non-decreasing allocation. In fact, the stock of capital cannot grow to a size that exceeds $\bar{k}$, where $g^{\prime}(\bar{k})$ equals the utility discount rate. ${ }^{6}$ This means that consumption cannot grow beyond $g(\bar{k})$, and thus, the introduction of such a "small" utility discount rate excludes allocations with a large inequality between the present and unfortunate generations and the future and fortunate generations. Hence, even though discounted utilitarianism as a criterion for social decision-making is inconsistent with the axiom of 'Equity', in Ramsey technologies it leads to outcomes that are consistent with 'Efficiency' and 'Equity' as long as the discount rate is sufficiently "small".

This attractive feature of discounted utilitarianism arises in Ramsey technologies since an efficient and stationary allocation has constant net capital productivity $g^{\prime}(k(y))$. In a Dasgupta-Heal-Solow, however, the net capital productivity $G_{k}(k, r, \ell)$ decreases and approaches zero along any efficient and non-decreasing allocation. This means that discounted utilitarianism will force consumption to approach zero in the long run, independently of how "small" the discount rate is, even if (E.3) is satisfied so that the set of efficient and non-decreasing allocations is non-empty. This in turn implies that

\footnotetext{
${ }^{6}$ Since the application of such a "small" discount rate leads to $k_{t}$ being bounded above, the resulting allocation is $y$-feasible in the terminology of Sect. 4.2 (cf. footnote 3). Hence, Prop. 2 applies and the given discounted utilitarian criterion can be substituted by an extended undiscounted utilitarian criterion (cf. Joshi [16] for a related but different statement in a special case of the Ramsey model). Thus, the introduction of pure time preference, which may appear to be without "intrinsic ethical appeal" and therefore "purely ad hoc" (Rawls [24], p. 298), is not needed to obtain appealing allocations in Ramsey technologies.
} 
discounted utilitarianism is what Page ([21], p. 198) calls a "fair weather criterion" that necessarily leads to outcomes inconsistent with the axioms of 'Efficiency' and 'Equity' in the more severe context of a Dasgupta-HealSolow technology. These results are summarized in Table 1.

These conclusions mean that - although discounted utilitarianism appeals to our ethical intuitions in the simple environment of Ramsey technologies - introducing positive discounting is not in general an appropriate way of achieving ethically desirable outcomes. In contrast, undiscounted utilitarianism is sufficiently malleable so that any ethically desirable outcome can be realized as long as such an allocation is consistent with 'Efficiency' and 'Equity'. Hence, in the context of utilitarianism there appears to be no ethical argument in favor of discounting.

Determining an intergenerational allocation amounts to nothing else than resolving the distributional conflict between the different generations. Following Atkinson [2] it is quite familiar in economics to have distributional objectives incorporated in symmetric additive social welfare functions where the consumption (or income) of every economic agent is evaluated by some utility function $u$. Then the degree of inequality aversion contained in the social welfare function is expressed by the degree of concavity of the utility function $u$ (cf. Cowell [7] for a general overview and Collard [6] for a specific application in the intergenerational context). In the static case this leads to a completely egalitarian distribution unless there are costs of redistribution. In the present intergenerational context, the condition of 'Immediate productivity' means that there are negative transfer costs from the present to the future. Referring to Okun's well-known "leaking bucket", Schelling ([25], p. 396) vividly describes such a situation by using the term 'incubation bucket' in which "the good things multiply in transit so that more arrives at the destination than was removed from the origin." Hence, if such productivity of the technology is assumed, efficient and non-decreasing allocations are consistent with maximization of a symmetric additive welfare function. This means that the familiar welfarist approach might be attractive to apply also for evaluating intergenerational allocations, even in the infinite case. ${ }^{7}$

\footnotetext{
${ }^{7}$ Following partly the same line of argument, Schelling ([25], p. 401) concludes: "The discount-rate question should disappear. In its place is what utility function to use in valuing future increments in other people's consumption. This is a real question, not a matter of mathematical convenience."
} 
That a more concave $u$ can substitute for a higher discount rate in skewing the intergenerational distribution in favor of earlier generations, thus slowing economic growth, has by interpreting the well-known Ramsey rule for optimal economic growth been observed for a long time (see e.g. Dasgupta and Heal [9], p. 292, as well as Fleurbaey and Michel [13], p. 294, and [14], p. 723). Here, we have shown in the context of linear and Ramsey technologies that whatever decreased inequality is implied by discounting can also be obtained by choosing a more concave utility function, since the utility function can always be adjusted so that a given efficient and non-decreasing allocation is obtained as the optimal choice without discounting. Such adjustment is even possible in Dasgupta-Heal-Solow technologies, where discounted utilitarianism, for any positive and constant discounting, leads to unacceptable treatment of generations in the distant future. Thus, this malleability of undiscounted utilitarianism makes it possible in the intergenerational context to determine optimal allocations that appeal to our ethical intuitions through applying complete and transitive social preferences that satisfy reasonable ethical axioms.

\section{REFERENCES}

1. Arrow, K.J. (1999). Discounting, morality, and gaming. In P.R. Portney and J.P. Weyant (eds.), Discounting and Intergenerational Equity. Washingon, DC: Resources for the Future.

2. Atkinson, A. (1970). On the measurement of inequality. Journal of Economic Theory, 2, 244-63.

3. Asheim, G.B., Buchholz, W. and Tungodden, B. (2000). Justifying sustainability. Forthcoming in Journal of Environmental Economics and Management.

4. Cass, D. and Mitra T. (1991). Indefinitely sustained consumption despite exhaustible natural resources. Economic Theory, 1, 119-46.

5. Chakravarty, S. (1969). Capital and Development Planning. Cambridge, MA: MIT Press.

6. Collard, D. (1994). Inequality aversion, resource depletion and sustainability. Economics Letters, 45, 513-5.

7. Cowell, D. (2000). Measurement of inequality. In A. B. Atkinson and F. Bourguignon (eds.), Handbook of Income Distribution, Vol. I. Amsterdam: Elsevier.

8. Dasgupta, P.S. and Heal, G.M. (1974). The optimal depletion of exhaustible resources. Review of Economic Studies, (Symposium), 3-28.

9. Dasgupta, P.S. and Heal, G.M. (1979). Economic Theory and Exhaustible Resources. Cambridge, UK: Cambridge University Press. 
10. Dasgupta, P.S. and Mäler, K.G. (1995). Poverty, institutions, and the environmental resource-base. In J. Behrman and T.N. Srinavasan (eds.), Handbook of Development Economics, Vol. III. Amsterdam: Elsevier.

11. Dasgupta, S. and Mitra, T. (1983). Intergenerational equity and efficient allocation of exhaustible Resources. International Economic Review, 24, 133-53.

12. Diamond, P. (1965). The evaluation of infinite utility streams. Econometrica, 33, 1707 .

13. Fleurbaey, M. and Michel, P. (1994). Optimal growth and transfers between generations. Recherches Economiques de Louvain, 60, 281-300.

14. Fleurbaey, M. and Michel, P. (1999). Quelques réflexions sur la croissance optimale. Revue économique, 50, 715-32.

15. Harsanyi, J.C. (1953). Cardinal utility in welfare economics and in the theory of risktaking. Journal of Political Economy, 61, 434-5.

16. Joshi, S. (1994), Duality between discounted and undiscounted models of economic growth. Economics Letters, 44, 403-6.

17. Koopmans, T.C. (1960). Stationary ordinal utility and impatience. Econometrica, 28, 287-309.

18. Kreps, D. and Porteus, E.L. (1979). Temporal von Neumann-Morgenstern and induced preferences". Journal of Economic Theory, 20, 81-109

19. Mirrlees, J.A. (1967). Optimal growth when technology is changing. Review of Economic Studies, 34, 95-124.

20. Mitra, T. (1978). Efficient growth with exhaustible resources in a neoclassical model. Journal of Economic Theory, 17, 114-29.

21. Page, T. (1977). Conservation and Economic Efficiency. Baltimore and London: The John Hopkins University Press.

22. Pigou, A.C. (1932). The Economics of Welfare. London: Macmillan.

23. Ramsey, F. (1928). A mathematical theory of saving. Economic Journal, 38, 543-59.

24. Rawls, J. (1971), A Theory of Justice. Oxford: Oxford University Press.

25. Schelling, T. (1995). Intergenerational Discounting. Energy Economics, 23, 395-401.

26. Solow, R.M. (1974). Intergenerational equity and exhaustible resources, Review of Economic Studies, (Symposium), 29-45.

27. Svensson, L.G. (1980). Equity among generations. Econometrica, 48, 1251-6.

28. Szpilrajn, E. (1930). Sur l'extension de l'ordre partial. Fundamenta Mathematicae, 16, $386-9$.

29. Weitzman, M. (1998), Why the far-distant future should be discounted at the lowest possible rate. Journal of Environmental Economics and Management, 36, 201-8. 